\title{
The association between polymorphisms near TMEM18 and the risk of obesity: a meta-analysis
}

\author{
Natalia Koj ${ }^{1}$, Łukasz Grochowalski , Justyna Jarczak,2, Weronika Wójtowicz ${ }^{1}$, Marta Sobalska-Kwapis 1,2, \\ Marcin Słomka ${ }^{1,2}$, Błażej Marciniak ${ }^{1,2}$ and Dominik Strapagiel ${ }^{1,2^{*}}$ (D)
}

\begin{abstract}
Background: Many studies have proposed that the pathogenesis of obesity has a genetic basis, with an important risk factor being the presence of polymorphisms in the region of the TMEM18 gene, which plays a significant role in feeding behaviour; however, subsequent studies among different ethnic populations and age groups have shown inconsistent results. Therefore, this present meta-analysis examines the relationship between TMEM18 polymorphisms with the risk of obesity with regard to age group and ethnic population.
\end{abstract}

Methods: A literature database search was conducted for available relevant studies investigating the association between obesity risk and the presence of rs6548238, rs4854344, rs11127485, rs2867125 and rs 7561317 polymorphisms in TMEM18. Pooled odds ratio (OR) and 95\% confidence intervals (95\% Cl) were calculated by either a fixedeffects model or random effect model based on a heterogeneity test. The meta-analysis of rs6548238 and its surrogates examined the relationships between 53395 obesity cases and 123972 healthy controls from 27 studies and published data from the POPULOUS collection (Poland).

Results: A significant association is observed between rs6548238 (and surrogate) and obesity risk, with $\mathrm{OR}=1.25$ (95\% Cl: 1.08-1.45). Regarding population type, a significant association was revealed among groups of Europeans with $\mathrm{OR}=1.32(1.10-1.59)$ and Mexicans with $\mathrm{OR}=1.39$ (1.13-1.73). However, a lack of statistical significance was noticed in groups in Asia with $\mathrm{OR}=1.11$ ( $95 \% \mathrm{Cl}: 0.86-1.42$ ). Regarding age, a significant association was observed among children with $\mathrm{OR}=1.28$ ( $95 \% \mathrm{Cl}: 1.18-1.39)$ but not in adults $\mathrm{OR}=1.21$ ( $95 \% \mathrm{Cl}$ : 0.92-1.58).

Conclusions: The polymorphisms near TMEM18 appear to play a role in the development of obesity. Our findings indicate that differences exist between ethnic populations and age groups, supporting those of a previous study showing the various effects of genetic factors on age and ethnic groups.

Keywords: Obesity, TMEM18, Meta-analysis

*Correspondence: dominik.strapagiel@biol.uni.lodz.pl

${ }^{1}$ Biobank Lab, Department of Molecular Biophysics, Faculty of Biology

and Environmental Protection, University of Lodz, Lodz, Poland

Full list of author information is available at the end of the article

\section{Background}

Obesity is a nutritional disorder associated with weight gain [1] caused by extended maintenance of positive energy balance, i.e. where the energy consumed is higher than energy expended [2]. This phenomenon leads to abnormal or excessive fat accumulation [3], which entails the number of mechanisms impairing health. Excessive body weight greatly increases the risk of chronic disease, 
including depression, type 2 diabetes, cardiovascular disease or certain types of cancer [4]. Unfortunately, 2016 World Health Organisation data indicates that over 650 million adults were obese worldwide, a figure that nearly tripled since 1975 [5].

Obesity is classified by Body Mass Index (BMI), an index of weight-for-height defined as weight in kilograms divided by the square of height in meters $\left(\mathrm{kg} / \mathrm{m}^{2}\right)$. In adults, the threshold for obesity is considered to be a BMI of 30 [5], while age and sex-specific BMI-for-age percentile curves are used to define obesity in children: the Center for Disease Control and Prevention defines obesity as BMI values greater than the 95th percentile for children of the same age and sex [6]. Obese children are likely to stay obese into adulthood and they more easily develop weight-related diseases at a younger age [7]. As human age may have a significant impact on the manifestation of obesity, many studies concerning obesity are presented with regard to a specific age group [8]. In addition, differences in the prevalence of obesity have also been observed across diverse ethnic groups; while these disparities may be caused by lifestyle, socioeconomic status and access to health care, they may be influenced by varying levels of biological susceptibility for obesity [9].

Obesity is considered by many researchers to be a heritable disease [10], and many polymorphisms in the human genome could contribute to its development. Understanding the genetic factors affecting obesity will allow easier identification of its cause [11]. Previous studies have found polymorphisms in human chromosome 2 p25 to be associated with obesity [3]. The TMEM18 gene, which is located at chromosome 2 p25.3, encodes the transmembrane protein 18 (TMEM18), which is located in the nuclear membrane. This protein is reported to be involved in weight regulation through transcriptional repression [12]. TMEM18 is expressed in several regions of the brain, including the hypothalamus, which is responsible for the regulation of feeding behaviour. The relationship between TMEM18 and changes in BMI has been confirmed by a third wave of GWAS (Genome-wide association study) [11], and subsequently confirmed by two independent follow-up studies [13, 14]. Apart from its involvement in obesity, TMEM18 may also influence cell migration by regulating neuronal stem cell mobility [15].

With the discovery of an apparent relationship between the TMEM18 region and obesity, there is a clear need to determine more precisely the effect size of polymorphisms rs6548238, rs4854344, rs11127485, rs2867125, and rs7561317 localised near the gene itself with regard to age and population type. Therefore, the present metaanalysis reviews a range of data meeting the required criteria, with the age categorization.

\section{Methods}

\section{Material and search strategy}

Identification of relevant studies concerning the association of rs6548238 rs4854344, rs11127485, rs2867125, and rs7561317 polymorphisms with obesity was conducted by systematic literature search from PubMed, Science Direct, Web of Science databases and GWAS catalogue. The following search terms were used: obesity AND (TMEM18 OR GWAS). Obtained results were divided into two categories: age and population. No restriction was placed on the time period, sample size or language. If more than one article was published using the same case series, only the original study was included.

\section{Inclusion and exclusion criteria}

The present meta-analysis included genetic association studies based on cohort or case-control models, in which the case subjects were obese and the control subjects were individuals within the normal BMI range. The following inclusion criteria were applied: (a) case-control or cohort studies presenting original data on the associations between the risk of obesity and TMEM18 polymorphisms (rs6548238 rs4854344, rs11127485, rs2867125 or rs7561317), (b) sufficient data for the calculation of odds ratio $(\mathrm{OR})$ with the $95 \%$ confidence interval $(95 \% \mathrm{CI})$ or calculated OR with 95\% CI. The following exclusion criteria were applied: (a) review articles and meta-analysis, (b) studies on the association between other gene polymorphisms and obesity risks, (c) no information about number of alleles and number of cases and controls (d) studies based on non-human models (e) quantitative traits such as Body Mass Index or Body Fat Percentage since the data were not uniform (beta with $95 \% \mathrm{CI}$, mean with standard deviation or mean with $95 \% \mathrm{CI}$ ).

\section{Data extraction}

Two researchers collected data independently. Disagreements were resolved by discussion with a third researcher. The following information was extracted from each study: (a) name of the first author, (b) year of publication, (c) country of origin, (d) ethnicity, (e) sample size, (f) association of the SNPs with obesity (OR and 95\% CI), (g) analysed polymorphism, (h) number of case and controls, (i) mean age of case and controls.

\section{Description of additional dataset}

Additional data from adults of Polish origin were collected between 2010-2012 within the TESTOPLEK research project and registered as the POPULOUS collection [16, 17] (POPUlation-LOdz UniverSity Biobank) at the Biobank Lab of the Department of Molecular Biophysics, University of Lodz. The POPULOUS population collection is currently registered 
in Directory (v. 4.0) of BBMRI-ERIC consortium under the registration number bbmri-eric:ID:PL BLUL:collection:POPULOUS_BLUL. POPULOUS contains saliva samples from over 10,000 volunteers from all over the Poland [18]. The participants, as well as the methods used for DNA extraction, quantification and genotyping are described elsewhere [17].

The approval for the present study was obtained from the University of Lodz Review Board (KBBN-UL/ II/2014), and each participant from the POPULOUS study gave their written consent to take part. All procedures were performed in accordance with the Declaration of Helsinki (ethical principles for medical research involving human subjects) [17].

The BMI of each participant was calculated from the standard formula: $\mathrm{BMI}=$ weight $/$ height $^{2}$, based on selfassessment of height and weight controlled by trained pollsters. People were considered as obese when BMI values were $\geq 30$, and were normal when BMI was in the range of 18.5-24.9 [19]. Allele frequency of additional data derived from POPULOUS collection was calculated using PLINK 1.07. Differences in the distributions of allele frequencies between normal weight and obese people were evaluated using an additive model.

The results indicate that 6047 unrelated Polish adult subjects were enrolled in the study group. Of these, 3495 subjects remained after exclusion of underweight $(\mathrm{BMI}<18.5)$ and overweight (BMI in the range of 25.0-29.9) individuals. Following this, 3 334 individuals, including 827 obese cases $(\mathrm{BMI}>30)$ and 2667 control cases with normal weight (BMI in the range of 18.5-25.0), were successfully genotyped for SNPs rs6548238, rs2867125 and rs7561317. For rs4854344 there were 804 cases and 2592 controls. $24 \times 1$ Infinium HTS Human Core Exome (Illumina Inc., San Diego, CA, USA) microarrays were used for genotyping according to the protocol provided by the manufacturer.

\section{Quality assessment}

The Newcastle-Ottawa Scale [20] was used to assess the quality of studies included in the analysis. The analysis was conducted by two researchers independently, disagreements were resolved by discussion with a third researcher. The used methodology assesses studies in terms of Selection, Comparability and Exposure. The overall score is calculated in terms of stars awarded for each of nine questions. All studies included in the meta-analysis received at least seven stars (Additional file 8: Table S3), which suggested the high quality of the included publications.

\section{Data analysis}

The association between obesity risk and the presence of rs6548238, rs4854344, rs11127485, rs2867125 or rs7561317 polymorphisms was estimated by calculation of pooled ORs and $95 \% \mathrm{CI}$ in the allele model (C vs. T for rs6548238, T vs. G for rs4854344, for T vs. C for rs11127485, C vs. T, for rs 2867125 or $\mathrm{G}$ vs. A for rs7561317). The combined outcomes were displayed as forest plots. Statistical differences of the pooled ORs were assessed using Z-test, $p \leq 0.05$ was considered as statistically significant. The statistical analysis of the extracted data was conducted using Review Manager 5.3 [21]. This program was used to calculate the pooled effect size and sensitivity analysis and to assess the risk of publication bias.

Cochran's Chi-squared test (based on Q test) was used to evaluate heterogeneity between studies, a $p$-value threshold of 0.1 was considered as statistically significant. The heterogeneity between the studies was also tested by $\mathrm{I}^{2}$ statistics; $\mathrm{I}^{2}$ values of at least $50 \%$ were taken as indicators of heterogeneity. When heterogeneity existed, a random effect model was used to evaluate the pooled ORs and $95 \%$ CIs, otherwise a fixed effect model was used.

Potential publication bias was assessed via visual inspection of the funnel plot, with an asymmetric funnel plot indicating publication bias. To identify the source of heterogeneity, a sensitivity analysis was applied by removing individual studies from the data for children or adults. Subgroup analysis was performed based on population type (European, Asian or Mexican) and age: adults ( $>18$ years) vs. children ( $\leq 18$ years). A total of five polymorphisms were evaluated independently (rs6548238, rs4854344, rs11127485, rs2867125, rs7561317), as was rs6548238 and its surrogates.

The following studies were included in the meta-analysis: Albuquerque et al. [22], Almen et al. [23], Bradfield et al. [24], Cheung et al. [25], den Hoed et al. [26], Dusatkova et al. [27], Garcia-Solis et al. [28], Hong et al. [29], Hotta et al. [30], Leon-Mimila et al. [31], Liu et al. [32], Lv et al. [33], Ozdemir-Erdogan et al. [34], Rask-Andersen et al. [35], Rask-Andersen et al. [36], Rouskas et al. [37], Sandholt et al. [38], Speliotes et al. [13], Srivastava et al. [39], Thomsen et al. [40], Wang et al. [41], Willer et al. [11], Zhao et al. [42], Zhu et al. [43].

\section{Results \\ Characteristics of the included individual studies}

The PRISMA (Preferred Reporting Items for Systematic Reviews and Meta-Analyses) flow chart explaining study selection and literature search is presented in Fig. 1. Searches of the databases using the keywords identified 3537 potentially relevant reports. All articles 


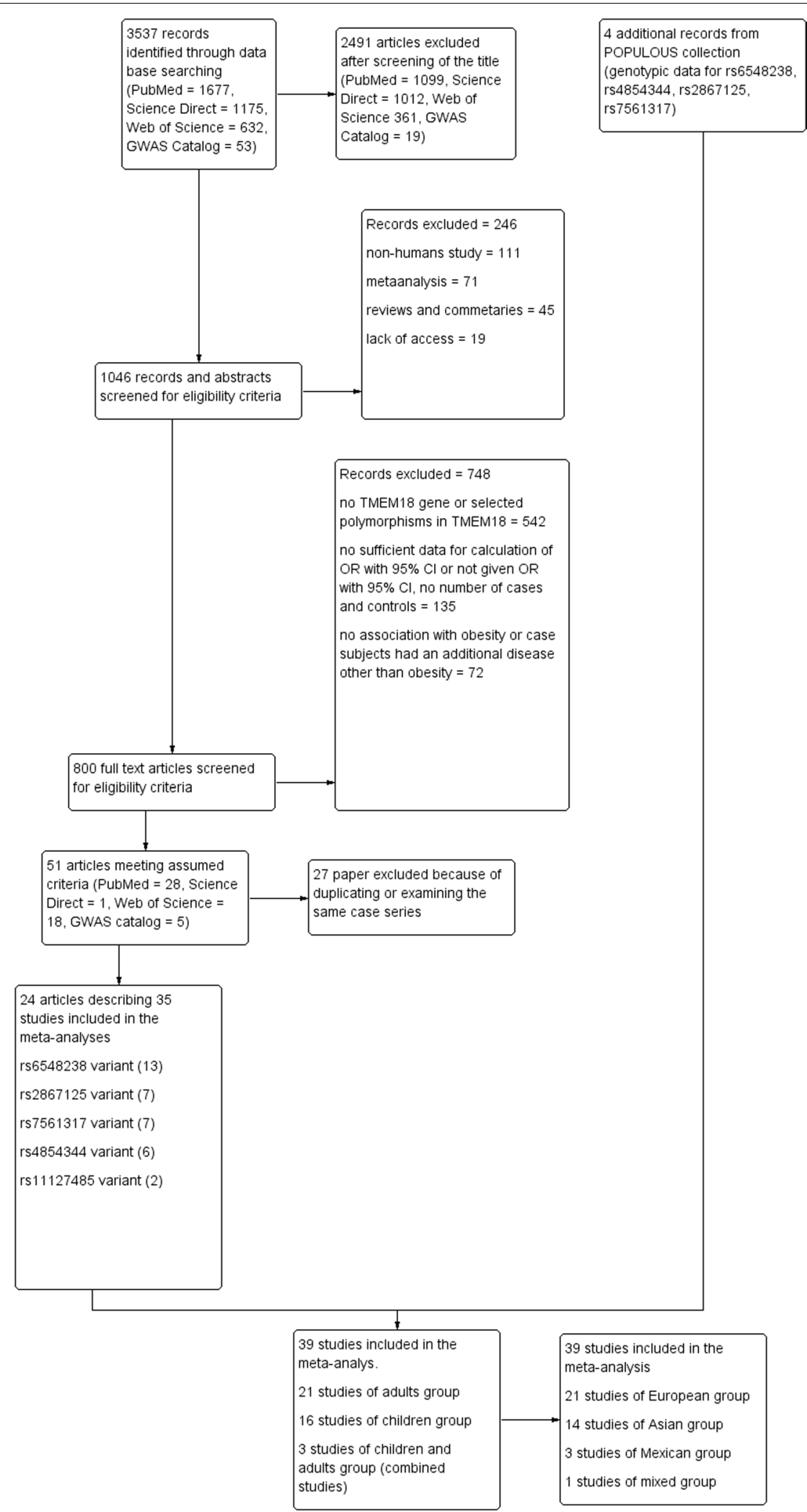

Fig. 1 PRISMA flow diagram for the meta-analysis. Study selection process according to Preferred Reporting Items for Systematic Reviews and Meta-Analyses (PRISMA) guidelines. The PRISMA template is created within RevMan 5.3 software 
were screened against the inclusion and exclusion criteria. After reading the titles, 2491 irrelevant studies were excluded. Another 246 studies were excluded after reading the abstracts and 748 after reading the full texts. After applying all inclusion and exclusion criteria, 25 articles and 35 studies from the literature search and four additional studies from POPULOUS collection were analysed. Eight articles included more than one study [23, 30, $31,35,36,39,42,44]$. The characteristics of the included studies are shown in Additional file 6: Table S1. Regarding population type, 14 studies were performed on Asian populations, 21 on European populations, three on Mexican populations and one was mixed. Among these studies, 21 focused on adults ( $\geq 18$ years), and 16 on children ( $<18$ years) and three were combined studies (children and adults together).

The sample size showed great variation, from $n=77$ to $n=40$ 872. Throughout the meta-analysis, if the study contained results for more than one polymorphism, only rs6548238 was selected. Detailed information about the studies selected for the meta-analysis is gathered in Additional file 6: Table S1.

\section{Heterogeneity}

The heterogeneity among studies was assessed by the Chi-squared test based on Q-test and the $\mathrm{I}^{2}$ statistics.
The results of the $\mathrm{I}^{2}$ test found low heterogeneity concerning rs6548238 and its surrogate in the group of children $\left(\mathrm{I}^{2}=54 \%, p=0.01\right)$. Therefore the fixed effect model was used for further analysis. As the group of adults demonstrated high heterogeneity $\left(\mathrm{I}^{2}=99 \%, p<0.00001\right)$, the random effect model was used. Regarding population type, low heterogeneity was only observed in the Mexican group $\left(\mathrm{I}^{2}=41 \%, p=0.18\right)$; higher heterogeneity was observed among the European and Asian groups $\left(\mathrm{I}^{2}=99 \%, p<0.00001\right.$ and $\mathrm{I}^{2}=83 \%, p<0.00001$ respectively).

\section{Quantitative data synthesis}

The overall results showed that rs6548238 and its surrogate was significantly associated with obesity risk $(\mathrm{OR}=1.25$; 95\% CI: 1.08-1.45) (Fig. 2). In addition, a significant association was observed in children $(\mathrm{OR}=1.28$; 95\% CI: 1.18-1.39) (Fig. 3) but not in adults (OR=1.21; 95\% CI: 0.92-1.58) (Fig. 4). In the subgroup stratified by population type, the effect size was significant among both European (OR $=1.32$; 95\% CI: 1.10-1.59) (Fig. 5) and Mexican (OR=1.39; 95\% CI: 1.13-1.73) (Fig. 6) but not in Asian populations $(\mathrm{OR}=1.11$; 95\% CI: $0.86-1.42)$ (Fig. 7).

Based on 1000 Genomes Project data, polymorphism rs6548238 is used in the main analysis since it is in a

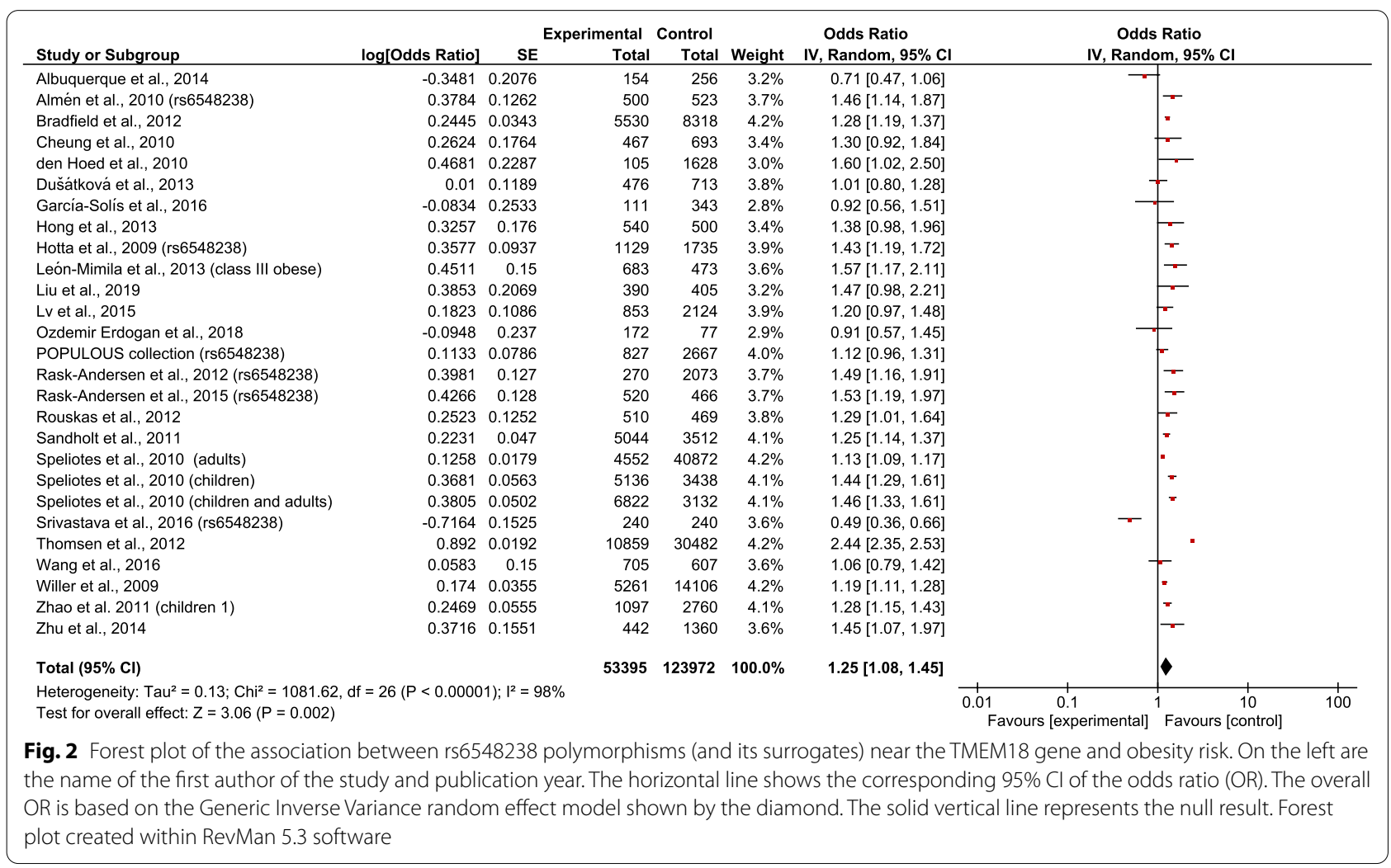






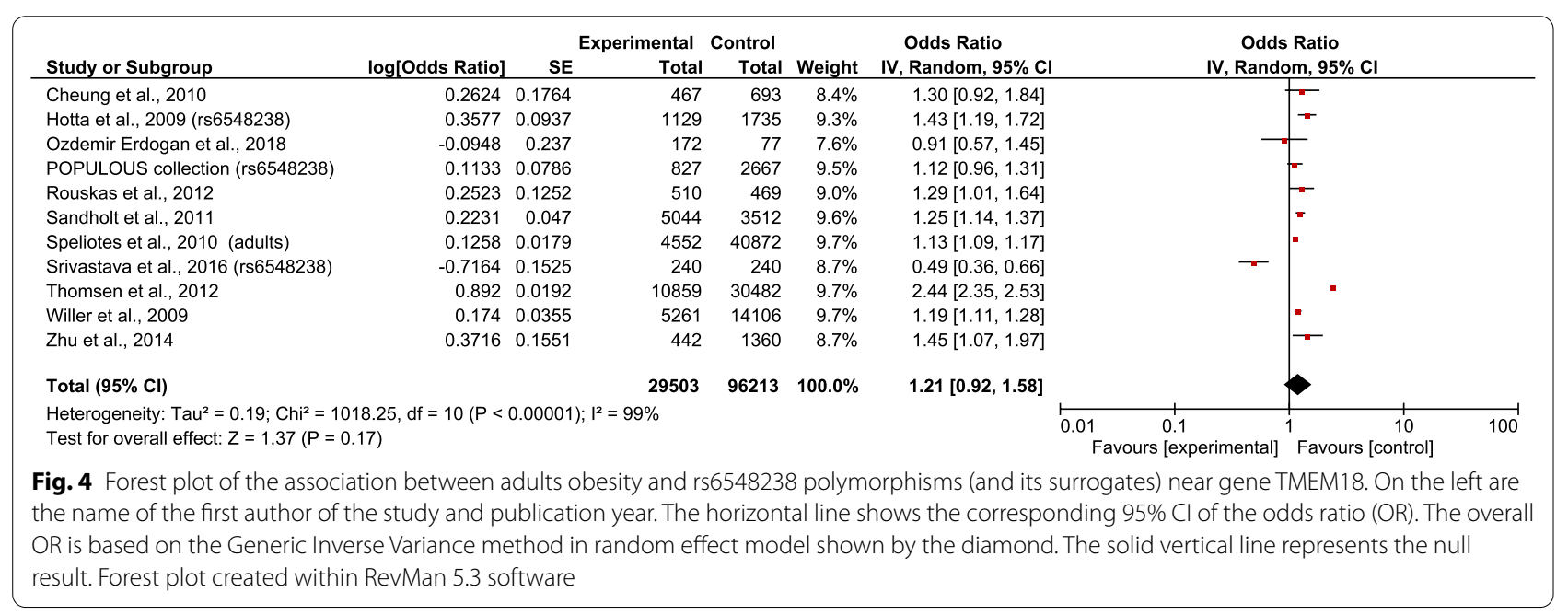

high linkage disequilibrium with $\operatorname{rs} 4854344 \quad\left(D^{\prime}=1\right.$; $r=1$ in CEU (Utah Residents $(\mathrm{CEPH})$ with Northern and Western European ancestry); $D^{\prime}=1 ; r=1$ in $\mathrm{CHB}$ (Han Chinese in Beijing, China); $D^{\prime}=1 ; r=1$ in $\mathrm{MXL}$ (Mexican Ancestry from Los Angeles USA), rs11127485 ( $\mathrm{D}^{\prime}=1 ; \mathrm{r}=1$ in CEU; $\mathrm{D}^{\prime}=1 ; \mathrm{r}=1$ in $\mathrm{CHB}$; $\mathrm{D}^{\prime}=1, \mathrm{r}=1$ in $\mathrm{MXL}), \mathrm{rs} 2867125\left(\mathrm{D}^{\prime}=1 ; \mathrm{r}=0.964\right.$ in $\mathrm{CEU} ; \mathrm{D}^{\prime}=1$; $\mathrm{r}=1$ in $\mathrm{CHB} ; \mathrm{D}^{\prime}=1 ; \mathrm{r}=1$ in $\mathrm{MXL}$ ) and $\mathrm{rs} 7561317$ $\left(D^{\prime}=1 ; r=1\right.$ in $C E U ; D^{\prime}=1 ; r=1$ in $C H B ; D^{\prime}=1 ; r=1$ in MXL).

In the analysis of each polymorphism without division into subgroups, independently pooled ORs indicate that allele $\mathrm{C}$ of $\mathrm{rs} 6548238(\mathrm{OR}=1.19 ; 95 \% \mathrm{CI}$ : 0.98-1.64) (Additional file 1: Fig. S1) was not related with the risk of obesity; however, some of the other analysed alleles, including allele $\mathrm{T}$ of $\mathrm{rs} 4854344(\mathrm{OR}=1.41$;
95\% CI: 1.24-1.60) (Additional file 2: Fig. S2) allele T of rs11127485 (OR=1.49; 95\% CI: 1.20-1.87) (Additional file 3: Fig. S3) and allele $C$ of $r s 2867125$ (OR $=1.29 ; 95 \%$ CI: 1.16-1.43) (Additional file 4: Fig. S4) were associated with the risk of obesity. The allele $\mathrm{G}$ of rs7561317 did not appear to demonstrate any significant relationship with obesity (OR 1.08; 95\% CI: 0.88-1.32) (Additional file 5: Fig. S5).

\section{Publication bias and sensitivity analysis}

Any publication bias regarding rs6548238 and its surrogates in the overall analysis was determined using funnel plots. The funnel plot revealed some asymmetry caused by the small study effects, or by the publication (Fig. 8).

To assess whether a single study could influence the main results, each study from the overall analysis was 


\begin{tabular}{|c|c|c|c|c|c|c|c|c|c|}
\hline Study or Subgroup & log[Odds Ratio] & \multicolumn{2}{|c|}{ Experimental } & \multicolumn{2}{|l|}{ Control } & $\begin{array}{c}\text { Odds Ratio } \\
\text { IV, Random, } 95 \% \mathrm{Cl}\end{array}$ & \multicolumn{3}{|c|}{$\begin{array}{c}\text { Odds Ratio } \\
\text { IV, Random, } 95 \% \mathrm{Cl}\end{array}$} \\
\hline Albuquerque et al., 2014 & -0.3481 & 0.2076 & 154 & 256 & $5.1 \%$ & $0.71[0.47,1.06]$ & & & \\
\hline Almén et al., 2010 (rs6548238) & 0.3784 & 0.1262 & 500 & 523 & $6.0 \%$ & $1.46[1.14,1.87]$ & & $=$ & \\
\hline Bradfield et al., 2012 & 0.2445 & 0.0343 & 5530 & 8318 & $6.7 \%$ & $1.28[1.19,1.37]$ & & $=$ & \\
\hline den Hoed et al., 2010 & 0.4681 & 0.2287 & 105 & 1628 & $4.9 \%$ & $1.60[1.02,2.50]$ & & 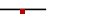 & \\
\hline Dušátková et al., 2013 & 0.01 & 0.1189 & 476 & 713 & $6.1 \%$ & $1.01[0.80,1.28]$ & & - & \\
\hline POPULOUS collection (rs6548238) & 0.1133 & 0.0786 & 827 & 2667 & $6.5 \%$ & $1.12[0.96,1.31]$ & & + & \\
\hline Rask-Andersen et al., 2012 (rs6548238) & 0.3981 & 0.127 & 270 & 2073 & $6.0 \%$ & $1.49[1.16,1.91]$ & & - & \\
\hline Rask-Andersen et al., 2015 (rs6548238) & 0.4266 & 0.128 & 520 & 466 & $6.0 \%$ & $1.53[1.19,1.97]$ & & $\sigma$ & \\
\hline Rouskas et al., 2012 & 0.2523 & 0.1252 & 510 & 469 & $6.0 \%$ & $1.29[1.01,1.64]$ & & $=$ & \\
\hline Sandholt et al., 2011 & 0.2231 & 0.047 & 5044 & 3512 & $6.6 \%$ & $1.25[1.14,1.37]$ & & $=$ & \\
\hline Speliotes et al., 2010 (adults) & 0.1258 & 0.0179 & 4552 & 40872 & $6.7 \%$ & $1.13[1.09,1.17]$ & & - & \\
\hline Speliotes et al., 2010 (children) & 0.3681 & 0.0563 & 5136 & 3438 & $6.6 \%$ & $1.44[1.29,1.61]$ & & $=$ & \\
\hline Speliotes et al., 2010 (children and adults) & 0.3805 & 0.0502 & 6822 & 3132 & $6.6 \%$ & $1.46[1.33,1.61]$ & & $=$ & \\
\hline Thomsen et al., 2012 & 0.892 & 0.0192 & 10859 & 30482 & $6.7 \%$ & $2.44[2.35,2.53]$ & & - & \\
\hline Willer et al., 2009 & 0.174 & 0.0355 & 5261 & 14106 & $6.7 \%$ & $1.19[1.11,1.28]$ & & $=$ & \\
\hline Zhao et al. 2011 (children 1) & 0.2469 & 0.0555 & 1097 & 2760 & $6.6 \%$ & $1.28[1.15,1.43]$ & & 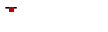 & \\
\hline Total $(95 \% \mathrm{Cl})$ & & & 47663 & 115415 & $100.0 \%$ & $1.32[1.10,1.59]$ & & $\nabla$ & \\
\hline $\begin{array}{l}\text { Heterogeneity: } \mathrm{Tau}^{2}=0.13 ; \mathrm{Chi}^{2}=1012.56 \\
\text { Test for overall effect: } Z=2.93(P=0.003)\end{array}$ & $=15(P<0.0000$ & $1) ; I^{2}=99 \%$ & & & & & 0.1 & & 100 \\
\hline
\end{tabular}

Fig. 5 Forest plot of the association between European obesity and rs6548238 polymorphisms (and its surrogates) near gene TMEM18. On the left are the name of the first author of the study and publication year. The horizontal line shows the corresponding $95 \% \mathrm{Cl}$ of the odds ratio (OR). The overall OR is based on the Generic Inverse Variance method in random effect model shown by the diamond. The solid vertical line represents the null result. Forest plot created within RevMan 5.3 software

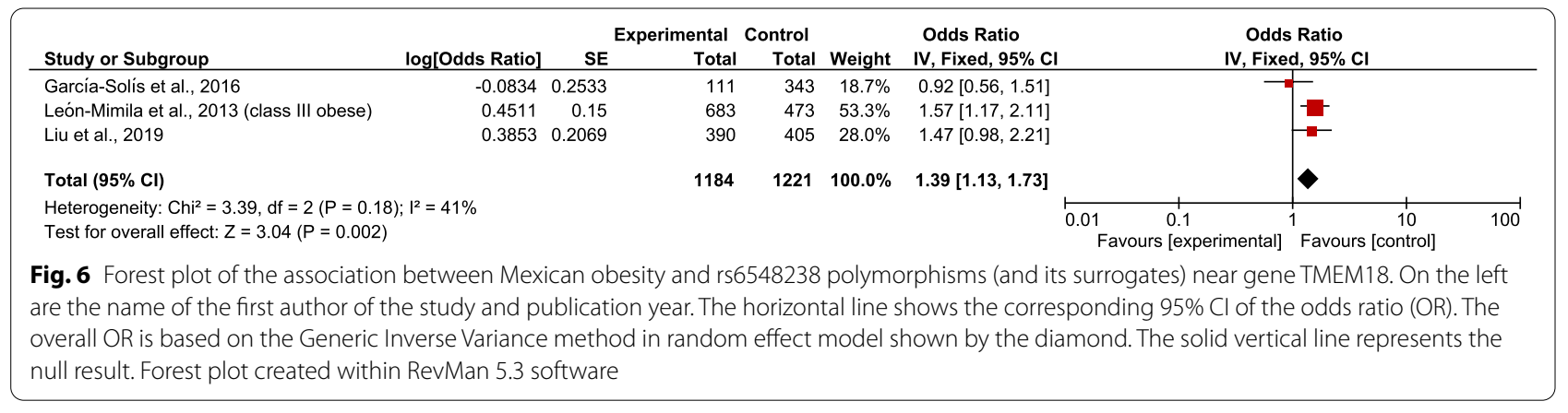

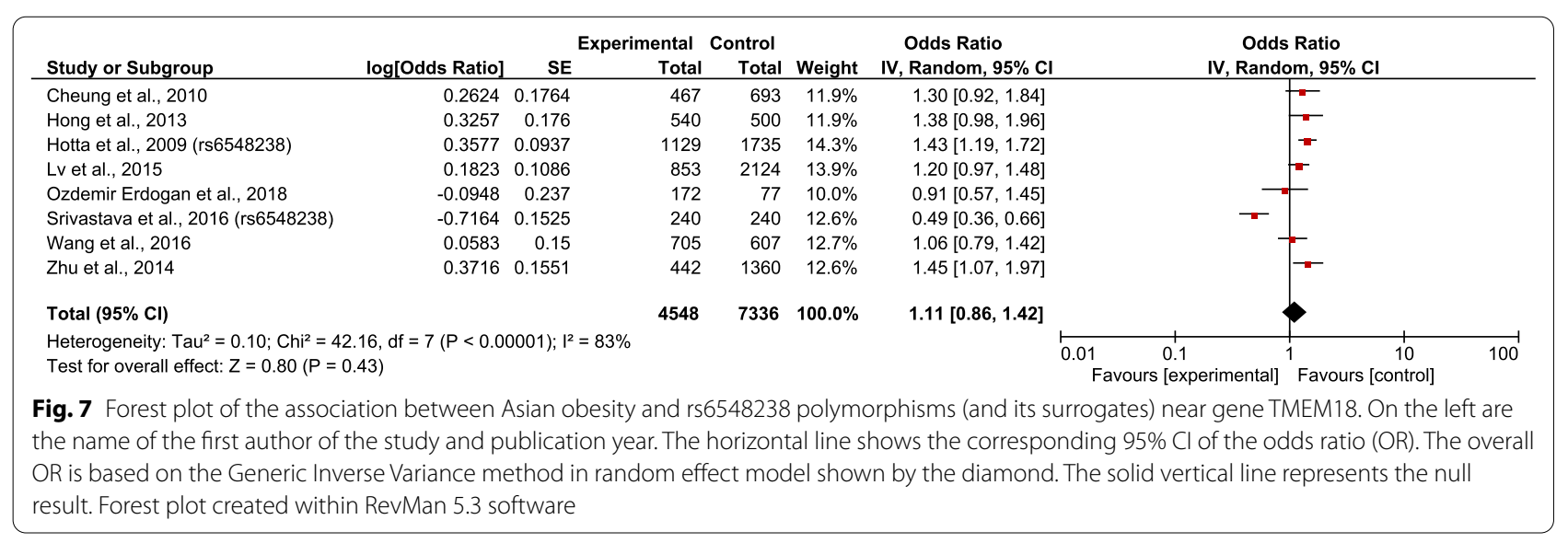




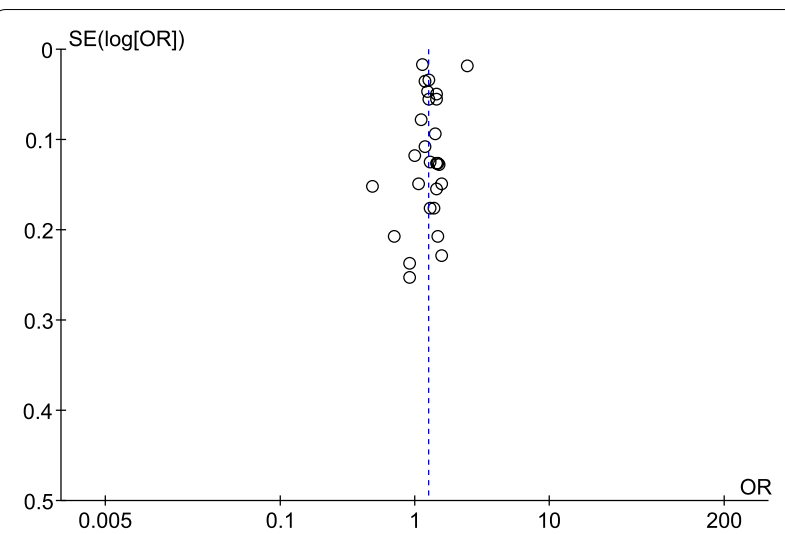

Fig. 8 Funnel plot of Odds Ratio vs. Standard Error for log OR using a random effect model to evaluate publication bias for the effect of polymorphism rs6548238 and its proxy obesity. Funnel plot created within forest plot created using RevMan 5.3 software

excluded. This allowed us to evaluate the influence of each study on the pooled effect size and the heterogeneity of the main results. However, the removal of any individual study from the data set did not substantially influence the OR in the overall analysis (Additional file 7: Table S2).

\section{Discussion}

Studies examining the effect of genetics on obesity allowed to find new genetic factors involved in the pathogenesis of this disease. One of the studied regions was p25 of human chromosome 2, which is near the gene TMEM18. Some studies indicate a clear correlation between the polymorphisms found in this region and the risk of obesity $[11,12,32,45]$, while others indicate no significant changes [28, 33]. The present meta-analysis was performed to evaluate the association of SNPs near TMEM18 with obesity with regard to age, i.e. children and adults, as well as population type. If TMEM18 polymorphisms serve as risk factors for obesity, then it would be reasonable to assume that the alleles: $\mathrm{C}$ of rs6548238, $\mathrm{T}$ of rs4854344, $\mathrm{T}$ of rs11127485, C of rs2867125, G of rs7561317 will occur more often in obese people. To clarify these inconsistencies, the present meta-analysis was performed.

Most research has focused on the relationship between genetic factors and obesity-related traits among obese individuals, using lean individuals as a control group [17, 46, 47]. Many studies have carried out analyses involving the evaluation of BMI-increasing alleles with separation of ethnic [48] or age [49] groups. There is evidence that influence of genetic factors on the development of obesity differs among populations [50]. There is also evidence that the effects of common genetic variants on
BMI profiles vary between life periods [51-54]. Obesity is a multifactorial and complex disease with a range of environmental, socioeconomic, behavioural and genetic influences: the significant increase in the number of obese people observed over the last few decades cannot be related solely to genetics. This suggests that environmental and behavioural factors are mostly responsible for obesity $[55,56]$. Many studies have noted that the genetic contribution to BMI increases during childhood, but then decreases during adulthood, possibly due to the cumulative effects of many factors [57]. Adults are subject to a longer period of exposure to environmental, behavioural and socioeconomic factors which contribute to the development of obesity. The effect size of genetic factors which can predispose to obesity also differs between different populations across the world; such differenced may be associated with disparities in physiological responses to fat storage or different body shapes.

A key problem for the meta-analysis of genetic studies is presented by their frequent heterogeneity; this arises through various biases due to population stratification, misclassification of clinical outcome, genotyping errors and the overestimation of genetic effects in the original study, as well as a difference in the pattern of LD structure across populations [58]. In the present meta-analysis, greater heterogeneity was observed in the group of adults than the group of children; this difference is connected with the wider age range and the longer period of exposure to environmental and socioeconomic factors which affect obesity.

The strengths of the current study include the relatively large sample size from people around the world, the robustness of statistical analysis and additional data for meta-analysis (POPULOUS collection data). Despite all of these strengths, some limitations should be addressed. OR with 95\% CI from genetic data was used to evaluate the sole genetic influence; however, when it was not given, calculated OR with $95 \%$ CI was used after covariate adjustment from the individual study. The potential interactions between the genetic factors and environmental factors were not addressed due to insufficient data, which might also affect the accuracy of the results.

The second limitation concerns the variation in BMI cut-offs for obesity between studies. Most studies used the basic classification of obesity $(\mathrm{BMI} \geq 30)$ and normal weight (BMI 18.5-24.9); however, in some studies, mostly among Asian populations, other BMI thresholds were used for obesity (e.g. BMI $\geq 27.5$ ) and normal weight (e.g. BMI 18.5-23.0) (Additional file 6: Table S1). It is possible that the authors customized these ranges to better fit them to a particular studied population. These differences suggest that these ranges may be dependent on population type, and as such, could differ between European, Asian 
or other populations. Therefore, their comparison may be not so obvious. This was true for both adults and children, because some studies have used customized values of BMI percentiles to define obesity or normal weight in children.

The present meta-analysis is the first to systematically explore the association between TMEM18 polymorphisms and obesity across different population types based on ethnicity and age. Our findings indicate that rs6548238 was significantly associated with an increased risk of obesity and similar trends were found among subgroups of European and Mexican origin but not Asian. While the presence of this polymorphism appears to have a significant influence on obesity among children, no significant association was found with obesity risk among adults.

\section{Conclusions}

The results of this meta-analysis suggest an association between rs6548238 polymorphisms and its surrogate near TMEM18 and the risk of obesity. Differences appear to exist between ethnic populations and age groups. Our findings support those of a previous study showing the various effect of genetics in age and ethnic groups.

\section{Abbreviations}

BBMRI-ERIC: Biobanking and Biomolecular Resources Research InfrastructureEuropean Research Infrastructure Consortium; BMI: Body Mass Index; CEU: Utah Residents (CEPH) with Northern and Western European ancestry, from 1000 Genome Project; CHB: Han Chinese in Beijing, China, from 1000 Genome Project; GWAS: Genome-wide Association Study; MXL: Mexican ancestry from Los Angeles USA, from 1000 Genome Project; OR: Odds ratio; TMEM18: Transmembrane protein 18.

\section{Supplementary Information}

The online version contains supplementary material available at https://doi. org/10.1186/s12920-021-01025-7.

\section{Additional file 1: Fig. S1. Meta-analysis of the association between} rs6548238 and obesity risk using random effect model. Forest plot created within RevMan 5.3 software.

Additional file 2: Fig. S2. Meta-analysis of the association between rs4854344 and obesity risk using random effect model. Forest plot created within RevMan 5.3 software.

Additional file 3: Fig. S3. Meta-analysis of the association between rs 11127485 and obesity risk using fixed effect model. The size of the red box corresponding to each study is proportional to the sample size. Forest plot created within RevMan 5.3 software.

Additional file 4: Fig. S4. Meta-analysis of the association between rs2867125 and obesity risk using random effect model. Forest plot created within RevMan 5.3 software.

Additional file 5: Fig. S5. Meta-analysis of the association between rs7561317 and obesity risk using random effect model. Forest plot created within RevMan 5.3 software.

Additional file 6: Table S1. Characteristics of studies included in the meta-analysis.

Additional file 7: Table S2. Sensitivity analysis of general results of rs6548238 and its surrogates.

Additional file 8: Table S3. The quality of studies included in the analysis.

\section{Acknowledgements}

The authors would like to thank Prof. Łukasz Pułaski and Edward Lowczowski for assistance with language editing.

\section{Authors' contributions}

NK conceived the study and participated in its design, data acquisition, literature search, analysis and interpretation of data, and drafting of the manuscript, $Ł G$ - participated in literature search, analysis and interpretation of data, and drafting of the manuscript, JJ_-participated in analysis and interpretation of data, and drafting of the manuscript, WW-participated in literature search, data acquisition and data analysis, MSK_-participated in sample collection, genotyping and data acquisition, MS - participated in sample collection, genotyping, data acquisition and drafting of the manuscript, BM-substantively revised the final manuscript, DS - conceived the study and participated in its design, participated in data analysis and interpretation, and critically revised the final approval of the manuscript version to be published. All authors have read and approved the final manuscript.

\section{Funding}

The study was funded by Polish Innovative Economy Operational Programme Grant 01.01.02-10-005/08 TESTOPLEK from the European Regional Development Fund, by Digital Poland Operational Programme Grant POPC.02.03.0100-0012/17 E-czlowiek.pl. from the European Regional Development Fund. DS, MS and MSK were supported by the Polish Ministry of Science and Higher Education grant DIR/WK/2017/01. The funders have no role in the design and conduct of this study, nor its analysis, the interpretation of data or the writing this manuscript.

\section{Availability of data and materials}

Data sharing is not applicable to this article as no datasets were generated or analysed during the current study with the exclusion of the dataset from the POPULOUS study. To apply for permission and access to the raw data from POPULOUS study, please contact directly with corresponding author.

\section{Declarations}

\section{Ethics approval and consent to participate}

Additional data from adults of Polish origin were collected between 2010 2012 within the TESTOPLEK research project and registered as the POPULOUS collection at the Biobank Lab of the Department of Molecular Biophysics, University of Lodz. The POPULOUS collection was registered in 2013 in the BBMRI catalogue of population collection (Biobanking and Biomolecular Resources Research Infrastructure). Approval for the study was obtained from the University of Lodz Ethics Review Board), each volunteer from POPULOUS collection gave their written consent to participate in the study. All procedures were performed in accordance with the Declaration of Helsinki (ethical principles for medical research involving human subjects).

\section{Consent for publication}

Not applicable.

\section{Competing interests}

The authors declare that they have no competing interests.

\section{Author details}

${ }^{1}$ Biobank Lab, Department of Molecular Biophysics, Faculty of Biology and Environmental Protection, University of Lodz, Lodz, Poland. ${ }^{2}$ BBMRI.PI Consortium, Wroclaw, Poland.

Received: 4 October 2020 Accepted: 28 June 2021

Published online: 06 July 2021

\section{References}

1. Dixon JB. The effect of obesity on health outcomes. Mol Cell Endocrinol. 2010;316(2):104-8.

2. Hill JO, Wyatt HR, Peters JC. Energy balance and obesity. Circulation. 2012;126(1):126-32. 
3. Herrera BM, Keildson S, Lindgren CM. Genetics and epigenetics of obesity. Maturitas. 2011;69(1):41-9.

4. Hruby AHF. The epidemiology of obesity: a big picture. Pharmacoeconomics. 2016;2016(33):673-89.

5. Obesity and overweight: World Health Organization; 2020 [Available from: https://www.who.int/news-room/fact-sheets/detail/obesity-andoverweight.

6. Childhood Overweight and Obesity: Centers for Disease Control and Prevention; 2020 [Available from: https://www.cdc.gov/obesity/childhood/ index.html.

7. Walley AJ, Blakemore A, Froguel P. Genetics of obesity and the prediction of risk for health. Hum Mol Genet. 2006;15 Spec No 2:R124-30.

8. Chapman IM. Obesity in old age. Front Horm Res. 2008;36:97-106.

9. Stryjecki C, Alyass A, Meyre D. Ethnic and population differences in the genetic predisposition to human obesity. Obes Rev. 2017;19(1):62-80.

10. O'Rahilly S, Faroogi IS. Human obesity: a heritable neurobehavioral disorder that is highly sensitive to environmental conditions. Diabetes. 2008;57(11):2905-10.

11. Willer CJ, Speliotes EK, Loos RJ, Li S, Lindgren CM, Heid IM, et al. Six new loci associated with body mass index highlight a neuronal influence on body weight regulation. Nat Genet. 2009;41 (1):25-34.

12. Larder R, Sim MFM, Gulati P, Antrobus R, Tung YCL, Rimmington D, et al. Obesity-associated gene TMEM18 has a role in the central control of appetite and body weight regulation. Proc Natl Acad Sci USA. 2017;114(35):9421-6.

13. Speliotes EK, Willer CJ, Berndt SI, Monda KL, Thorleifsson G, Jackson AU, et al. Association analyses of 249,796 individuals reveal 18 new loci associated with body mass index. Nat Genet. 2010;42(11):937-48.

14. Thorleifsson G, Walters GB, Gudbjartsson DF, Steinthorsdottir V, Sulem P, Helgadottir A, et al. Genome-wide association yields new sequence variants at seven loci that associate with measures of obesity. Nat Genet. 2009:41(1):18-24.

15. Gervasini G, Gamero-Villarroel C. Discussing the putative role of obesityassociated genes in the etiopathogenesis of eating disorders. Pharmacogenomics. 2015;16(11):1287-305.

16. Sobalska-Kwapis M, Smolarz B, Slomka M, Szaflik T, Kepka E, Kulig B, et al. New variants near RHOJ and C2, HLA-DRA region and susceptibility to endometriosis in the Polish population-The genome-wide association study. Eur J Obstet Gynecol Reprod Biol. 2017;217:106-12.

17. Sobalska-Kwapis M, Suchanecka A, Slomka M, Siewierska-Gorska A, Kepka E, Strapagiel D. Genetic association of FTO/IRX region with obesity and overweight in the Polish population. PLoS ONE. 2017;12(6):e0180295.

18. Dobrowolska S, Michalska-Madej J, Słomka M, Sobalska-Kwapis M, Strapagiel D. Biobank Łódź ${ }^{\circledR}$-population based biobank at the University of Łódź, Poland. Eur J TransI Clin Med. 2019;2(1):85-95.

19. Body mass index-BMI. World Health Organization; 2020 .

20. Peterson JaW, V and Losos, M and Tugwell, PJOOHRI and others. The Newcastle-Ottawa scale (NOS) for assessing the quality of nonrandomised studies in meta-analyses. Ottawa: Ottawa Hospital Research Institute. 2011.

21. Review Manager Web (RevMan Web). the Cochrane Collaboration; 2019

22. Albuquerque D, Nobrega C, Rodriguez-Lopez R, Manco L. Association study of common polymorphisms in MSRA, TFAP2B, MC4R, NRXN3, PPARGC1A, TMEM18, SEC16B, HOXB5 and OLFM4 genes with obesityrelated traits among Portuguese children. J Hum Genet 59(6):307-13.

23. Almen MS, Jacobsson JA, Shaik JH, Olszewski PK, Cedernaes J, Alsio J, et al. The obesity gene, TMEM18, is of ancient origin, found in majority of neuronal cells in all major brain regions and associated with obesity in severely obese children. BMC Med Genet. 2010;11:58.

24. Bradfield JP, Taal HR, Timpson NJ, Scherag A, Lecoeur C, Warrington NM, et al. A genome-wide association meta-analysis identifies new childhood obesity loci. Nat Genet 44(5):526-31.

25. Cheung CY, Tso AW, Cheung BM, Xu A, Ong KL, Fong CH, et al. Obesity susceptibility genetic variants identified from recent genome-wide association studies: implications in a chinese population. J Clin Endocrinol Metab. 95(3):1395-403.

26. den Hoed M, Ekelund U, Brage S, Grontved A, Zhao JH, Sharp SJ, et al. Genetic susceptibility to obesity and related traits in childhood and adolescence: influence of loci identified by genome-wide association studies. Diabetes. 2010;59(11):2980-8.
27. Dusatkova L, Zamrazilova H, Sedlackova B, Vcelak J, Hlavaty P, Aldhoon Hainerova I, et al. Association of obesity susceptibility gene variants with metabolic syndrome and related traits in 1,443 Czech adolescents. Folia Biol (Praha). 59(3):123-33.

28. Garcia-Solis P, Reyes-Bastidas M, Flores K, Garcia OP, Rosado JL, Mendez-Villa L, et al. Fat mass obesity-associated (FTO) (rs9939609) and melanocortin 4 receptor (MC4R) (rs17782313) SNP are positively associated with obesity and blood pressure in Mexican school-aged children. Br J Nutr. 2016:1-7.

29. Hong J, Shi J, Qi L, Cui B, Gu W, Zhang Y, et al. Genetic susceptibility, birth weight and obesity risk in young Chinese. Int J Obes (Lond). 37(5):673-7.

30. Hotta K, Nakamura M, Nakamura T, Matsuo T, Nakata Y, Kamohara S, et al. Association between obesity and polymorphisms in SEC16B, TMEM18, GNPDA2, BDNF, FAIM2 and MC4R in a Japanese population. J Hum Genet. 2009:54(12):727-31.

31. Leon-Mimila P, Villamil-Ramirez H, Villalobos-Comparan M, VillarrealMolina T, Romero-Hidalgo S, Lopez-Contreras B, et al. Contribution of common genetic variants to obesity and obesity-related traits in mexican children and adults. PLoS ONE. 2013;8(8):e70640.

32. Liu CT, Young KL, Brody JA, Olden M, Wojczynski MK, Heard-Costa N, et al. Sequence variation in TMEM1 8 in association with body mass index: Cohorts for Heart and Aging Research in Genomic Epidemiology (CHARGE) Consortium Targeted Sequencing Study. Circ Cardiovasc Genet. 2014;7(3):344-9.

33. Lv D, Zhang DD, Wang $H$, Zhang $Y$, Liang L, Fu JF, et al. Genetic variations in SEC16B, MC4R, MAP2K5 and KCTD15 were associated with childhood obesity and interacted with dietary behaviors in Chinese school-age population. Gene. 2015;560(2):149-55.

34. Erdogan MO, Avci K, Yildiz SH, Terzi ESA, Soylemez Z, Varol N, et al. Effect of gene polymorphisms in transmembrane protein 18 (TMEM18) and neuronal growth regulator 1 (NEGR1) on body mass index in obese subjects. Biotechnol Biotechnol Equip. 2018;32(6):1567-74.

35. Rask-Andersen M, Jacobsson JA, Moschonis G, Chavan RA, Sikder MA, Allzen E, et al. Association of TMEM18 variants with BMI and waist circumference in children and correlation of mRNA expression in the PFC with body weight in rats. Eur J Hum Genet. 2012;20(2):192-7.

36. Rask-Andersen M, Sallman Almen M, Jacobsson JA, Ameur A, Moschonis $G$, Dedoussis $G$, et al. Determination of obesity associated gene variants related to TMEM18 through ultra-deep targeted re-sequencing in a case-control cohort for pediatric obesity. Genet Res (Camb). 2015:97:e16.

37. Rouskas K, Kouvatsi A, Paletas K, Papazoglou D, Tsapas A, Lobbens S, et al. Common variants in FTO, MC4R, TMEM18, PRL, AIF1, and PCSK1 show evidence of association with adult obesity in the Greek population. Obesity (Silver Spring). 2012;20(2):389-95

38. Sandholt $\mathrm{CH}$, Vestmar MA, Bille DS, Borglykke A, Almind K, Hansen L, et al. Studies of metabolic phenotypic correlates of 15 obesity associated gene variants. PLoS ONE. 6(9):e23531.

39. Srivastava A, Mittal B, Prakash J, Srivastava P, Srivastava N. A multianalytical approach to evaluate the association of 55 SNPs in 28 genes with obesity risk in North Indian adults. Am J Hum Biol. 2017;29(2).

40. Thomsen M, Dahl M, Tybjaerg-Hansen A, Nordestgaard BG. beta2adrenergic receptor Thr164lle polymorphism, obesity, and diabetes: comparison with FTO, MC4R, and TMEM18 polymorphisms in more than 64,000 individuals. J Clin Endocrinol Metab. 2012;97(6):E1074-9.

41. Wang HJ, Hinney A, Song JY, Scherag A, Meng XR, Grallert H, et al. Association of common variants identified by recent genome-wide association studies with obesity in Chinese children: a case-control study. BMC Med Genet.17:7.

42. Zhao J, Bradfield JP, Zhang H, Sleiman PM, Kim CE, Glessner JT, et al. Role of BMI-associated loci identified in GWAS meta-analyses in the context of common childhood obesity in European Americans. Obesity (Silver Spring). 2010;19(12):2436-9.

43. Zhu J, Loos RJ, Lu L, Zong G, Gan W, Ye X, et al. Associations of genetic risk score with obesity and related traits and the modifying effect of physical activity in a Chinese Han population. PLoS ONE 9(3):e91442.

44. Scherag A, Dina C, Hinney A, Vatin V, Scherag S, Vogel Cl, et al. Two new Loci for body-weight regulation identified in a joint analysis of genomewide association studies for early-onset extreme obesity in French and german study groups. PLoS Genet. 2010;6(4):e1000916. 
45. Holzapfel C, Grallert H, Huth C, Wahl S, Fischer B, Doring A, et al. Genes and lifestyle factors in obesity: results from 12,462 subjects from MONICA/KORA. Int J Obes (Lond). 2010;34(10):1538-45.

46. Kolackov K, Laczmanski L, Lwow F, Ramsey D, Zdrojowy-Welna A, Tupikowska M, et al. The frequencies of haplotypes of FTO gene variants and their association with the distribution of body fat in non-obese poles. Adv Clin Exp Med. 2016;25(1):33-42.

47. Rosset I, Strapagiel D, Sitek A, Majewska M, Ostrowska-Nawarycz L, Żądzińska E. Association of FTO and TMEM18 polymorphisms with overweight and obesity in the population of Polish children. Anthropol Rev. 2016;79(1):17-33.

48. Mao L, Fang Y, Campbell M, Southerland WM. Population differentiation in allele frequencies of obesity-associated SNPs. BMC Genom. 2017;18(1):861.

49. Graff M, North KE, Richardson AS, Young KL, Mazul AL, Highland HM, et al. BMI loci and longitudinal BMI from adolescence to young adulthood in an ethnically diverse cohort. Int J Obes (Lond). 2017;41(5):759-68.

50. Isong IA, Rao SR, Bind MA, Avendano M, Kawachi I, Richmond TK. Racial and ethnic disparities in early childhood obesity. Pediatrics. 2018;141(1).

51. Graff M, Ngwa JS, Workalemahu T, Homuth G, Schipf S, Teumer A, et al. Genome-wide analysis of BMI in adolescents and young adults reveals additional insight into the effects of genetic loci over the life course. Hum Mol Genet. 2013;22(17):3597-607.

52. Hertel JK, Johansson S, Sonestedt E, Jonsson A, Lie RT, Platou CG, et al. FTO, type 2 diabetes, and weight gain throughout adult life: a meta-analysis of 41,504 subjects from the Scandinavian HUNT, MDC, and MPP studies. Diabetes. 2011;60(5):1637-44.

53. Song M, Zheng Y, Qi L, Hu FB, Chan AT, Giovannucci EL. Longitudinal analysis of genetic susceptibility and BMI throughout adult life. Diabetes. 2018;67(2):248-55

54. Winkler TW, Justice AE, Graff M, Barata L, Feitosa MF, Chu S, et al. The influence of age and sex on genetic associations with adult body size and shape: a large-scale genome-wide interaction study. PLoS Genet. 2015;11(10):e1005378.

55. Bouchard C. Current understanding of the etiology of obesity: genetic and nongenetic factors. Am J Clin Nutr. 1991;53(6 Suppl):1561S-S1565.

56. French SA, Story M, Jeffery RW. Environmental influences on eating and physical activity. Annu Rev Public Health. 2001;22:309-35.

57. Fulford AJ, Ong KK, Elks CE, Prentice AM, Hennig BJ. Progressive influence of body mass index-associated genetic markers in rural Gambians. J Med Genet. 2015;52(6):375-80.

58. Nakaoka H, Inoue I. Meta-analysis of genetic association studies: methodologies, between-study heterogeneity and winner's curse. J Hum Genet. 2009;54(11):615-23.

\section{Publisher's Note}

Springer Nature remains neutral with regard to jurisdictional claims in published maps and institutional affiliations.
Ready to submit your research? Choose BMC and benefit from:

- fast, convenient online submission

- thorough peer review by experienced researchers in your field

- rapid publication on acceptance

- support for research data, including large and complex data types

- gold Open Access which fosters wider collaboration and increased citations

- maximum visibility for your research: over 100M website views per year

At BMC, research is always in progress.

Learn more biomedcentral.com/submissions 